\title{
Retraction Note to: Air PM2.5 pollutant prediction and VR environmental art design index based on parameter estimation
}

\author{
Bin Zhang ${ }^{1}$
}

Published online: 3 November 2021

(c) Saudi Society for Geosciences 2021

Retraction Note to: Arabian Journal of Geosciences (2021) 14: 1738 https://doi.org/10.1007/s12517-021-08073-4

The Editor-in-Chief and the Publisher have retracted this article because the content of this article is nonsensical. The peer review process was not carried out in accordance with the Publisher's peer review policy. The author has not responded to correspondence regarding this retraction.

The original article can be found online at https://doi.org/10.1007/ s12517-021-08073-4.

Bin Zhang

zhangbin1414@163.com

1 Pingdingshan University, Pingdingshan 467000, Henan,

China 